Original Research Paper

\title{
Coaching for Monitoring Education Quality and Quality Assurance of Modular Education Program Based on Public- Private Partnership
}

\author{
Dulma Tsyrendashiyevna Dugarova, \\ Sesegma Zandaraevna Kimova and Natalia Anatolyevna Kazachek \\ Transbaikal State University, Chita, Russia
}

\author{
Article history \\ Received: 22-06-2016 \\ Revised: 25-10-2016 \\ Accepted: 5-11-2016 \\ Corresponding Author: \\ Natalia Anatolyevna Kazachek \\ Transbaikal State University, \\ Chita, Russia \\ Email: kazachekna@mail.ru
}

\begin{abstract}
A new stage in the development of quality management theory was the transition to knowledge management. Coaching is considered an important instrument of influence on the performance of individuals and the organization as a whole in terms of knowledge management. Modern management in the coaching style gives priority to look at employees as the main resource of the organization. The paper presents the analysis of the literature devoted to coaching development in Russia. The study was conducted based on the dualism of coaching, considered as an activity and as training. The paper focuses on coaching for monitoring the quality of education and education quality assurance of the modular education program implemented through public-private partnership, which also becomes the subject of coaching. The first part of the study was conducted using content analysis helping to identify and organize all mentions of coaching. The second part of the study was aimed at clarifying the role of the coach/organization. The paper identifies the major problems encountered in the coaching practice. The study covers two issues: (1) comparison of different approaches to the understanding of coaching, justification of the use of concept of "coaching" as a theoretical construct; (2) clarification of the role and purpose of "coach" in relation to the problematic field: expertise, accreditation, supervision, outsourcing and quality control. The article describes the experience of the Transbaikal State University in cooperation with coaching organizations and shows the specifics of public-private partnership regulation on the following levels: state, society, company, employer and high school.
\end{abstract}

Keywords: Coaching, Modular Education Program, Public-Private Partnership

\section{Introduction}

Today, the top priority of modern society is a quality education related to quality of changes occurring in the organization during the transition to a knowledge management. At the present time, there are various methods and approaches used in the field of knowledge management. Thus, the issues of managers' training are studied in the works of Bagdasarian (2012), Berulava (1999), Ershova (2005), Lapusta (2004), Marshev (2010), Simonov (1997), and others. The studies by Mescon et al. (1992), Valeva and Galev (1994), Dyrin (1996), Kudriashova (1986), Makarov (1989), Martynov (1991), Tarasov (2010) and others are devoted to the professional activity of managers. We should also mention the work by Milner et al. (2006) in which the quality of the work is related to knowledge management, availability of training system and knowledge management professionals (Nenashev, 2009).

Coaching is considered one of the newest tools of influence on the results of activity of individual employees and the whole organization that involves the use of different methods and techniques (Bobrova et al., 2002; Brod, 2005; Savkin and Danilova, 2003). Modern coaching-based management considers employees as a significant additional resource in the organization in which each employee is a unique creative personality, able to independently solve problems, take initiative, 
make choices, take responsibility and make decisions (Ermakova, 2007; Dobrotvorskii, 2003).

In Russia, the coaching appeared in 1997. Coaching has become widely used first of all by individuals and firms providing consulting services, conducting business trainings, etc., and become known as a business coaching or VIP-coaching ("elite coaching").

Foreign works on coaching have become widely known in our country (Whitmore, 1992). The first book about coaching published in Russian was the work of Whitmore (2001). A great contribution in the study of this issue was made by such researchers as Adizes (2009), O'Neill (2005), Grant and Greene (2005), Downey (2003), Jay (1999), Megginson and Clutterbuck (2004), Leonard (1998a; 1998b), Kimsey-House et al. (2004), Parsloe (1992), Reynolds (2003), Stacke (2006), Harris (2003). The works of Gallwey $(1981 ; 2000)$ were particularly important for the coaching issues conceptualization. He proposed a new methodology for staff development and career growth in different areas of activity based on the principles of sports games. His successor Whitmore (2001) was the one who coined the term "coaching" in wide use.

The first book in Russian devoted to coaching has become the work Savkin and Danilova (2003) "The Russian style coaching: courage for desires" (2003). To date, a vast array of national publications on coaching issues has been accumulated (Koval, 2009). First of all, we shall mention such authors as Avdeev (2006), Avetisov (2008), Bezruchko (2003), Gorshkova and Bukharkova (2006), Dovbnya (2003), Maksimov (2004), Ognev (2003), Prigozhin (2003), Rogachev (2003), Rybkin (2005), Samolianov (2008), Samoukina and Turkulets (2004), Sorokoumov (2006) and Chumakova (2013).

Among the economic investigations the work by Vylegzhanina (2007) is of special interest where the advantages of coaching as an effective technology for competitiveness provision are regarded as one of the most crucial factors reducing "restrictions of modern content of competitiveness management models and criteria for estimating its level in the context of increased significance of using the potential of the company's employees as a key factor of competitiveness (Vylegzhanina, 2007).

Among the sociological studies the work by Turkulets (2006) can be highlighted, which provides the author's scientific research on the development of social and managerial coaching technology to form labor motivation and corporate behavior of an organization's employees (Turkulets, 2006) is very significant. The author considers the coaching as a social technology of the partnership in the field of evaluation and correction of personal, professional and behavioral competencies of individual employees and their groups in order to form labor motivation and corporate behavior of company's employees.
The analysis of the literature and research of the issue show that coaching has never been the object of special study as monitoring of the quality of education and assurance of quality of modular education program.

\section{Concept Headings}

One of Russian educational modernization ways is change of emphasis from educational institutions as a whole to educational programs both in process of program implementation and during monitoring of results' quality verification. Due to above mentioned the subject of research concerning quality of education is both educational quality itself as the result of educational programs acquisition and guarantee of educational programs quality-human resources, material-andtechnical, informational resources, social environment in terms of each educational program.

Modular approach to educational programs is the trend of modern education it enables to build individual course for students. In terms of present research namely modular educational programs are studied.

Designated realias have actualized the need to resolve the basic contradictions: between the integration of the high school and private/public structures and the need to develop new coaching practices, taking into account regional resources - tools and methods for monitoring the quality of education and assurance of quality of modular education program.

There are several lacunae, in the coaching practice regarding the monitoring of the quality of education and education quality assurance:

- Insufficient consideration of new strategic and local formats of interaction between educational organizations and interested enterprises and business entities

- Undeveloped conceptual vision of monitoring of the quality of education and assurance of quality of modular education program based on public-private partnership in view of the modern trends in the regional economy

- Uncomplete reflection of the dynamics of statepublic regulation of content of modular education programs in the context of professional standards, national qualifications framework, federal state educational standards (hereinafter referred to as FSES), requirements and guidelines, criteria and indicators for professional and community associations

The identified contradictions and lacunae requiring resolution have defined the problem to be studied, which is to determine the conceptual framework and the methods of coaching for monitoring of the quality of education and assurance of quality of modular education program. 
All this was the point of departure in determining the target vector of the study. The objective of the study: to identify the main characteristics and trends of functioning of coaching as a means of teaching the monitoring of educational quality and assurance of quality of modular education program based on publicprivate partnership in accordance with the criteria and standards of the Association for Engineering Education of Russia (AEER).

In accordance with the objective, the following tasks have been set:

- Comparison of the different approaches to the understanding of coaching, justification of the use of concept of "coaching" as a theoretical construct

- Clarification of the role and purpose of "coach" in relation to the problematic field: expertise, accreditation, supervision, outsourcing and quality control

Quality of education of modern graduates, insufficient practical training call for defining new form and content of education to overcame and prevent such problems. That is why the novelty of the research is defined by the following:

Firstly, educational success mostly depends on interference of theoretical and practical training and readiness to mobilize all resources for it. We see the solution in couching - development education.

Secondly, it is worth mentioning that during their learning students significantly change their attitude towards university and often to the worse. Educational and cognitive motivation decrease often makes such students treat learning as a boring and hard duty. It also influences their further learning results. Encouraging interest for learning and acquiring profession we see as the role of coach. In terms of high education institution such mission can be accomplished by a scientific advisor, practice methodologist, "accredited advisor".

\section{Results}

The acquisition of knowledge, its storage, distribution and conversion to a modular education program that meets the needs of the regional economy, require the formation and implementation of certain organizational conditions. One of such conditions is the coaching. Coaching is a necessary condition for the formation of the actor capable to realize his potential.

Coaching shifts focus to the future and the present becomes the starting point. The goal of coaching is to elaborate a route toward the established objectives. The coaching can be used for both the elimination of deficiencies and the enhancement of the efficiency of a successful business.
Coaching is a process aimed at achieving the objectives in different spheres of life. This is a system of interaction with the coach, and if "coach" is literally a "wagon", so the coaching can lead to the following.

Coaching is a system, which:

- Allows moving from the area of the existing problem to the area of its effective solution

- Gives the opportunity to see new approaches and possibilities and to unleash the potential

Coaching is an organization of the activity with both an individual or a group and with the company, aimed at setting of one's own goals and the most rapid achievement of these goals by mobilizing the inner potential and development of innovative strategies for obtaining results. It can be said that the coaching helps the individual to learn rather than teaches him.

Coaching is a technique created at the intersection of psychology, management, philosophy, analytics and logic that is used to improve the efficiency and capacity of the person in order to solve his personal and business problems.

In the current practice, the professionals use different definitions of coaching, which reveal its developmental and interactive nature, such as: "Coaching is unlocking a person's potential to maximize their own performance" (Gallwey, 2000). "Coaching is the art of facilitating the performance, learning and development of another" (Downey, 2003). Coaching is a process built on the principles of partnership, which stimulates thinking and creativeness of customers, and inspires them to unleash as much as possible their personal and professional potential (ICF Russia, 2008)

Coaching is a focused, results-oriented and systematic process in which one person facilitates stable development of the other person or group of people, helping them to learn and promoting the personal growth of coaching client (Klarin, 2014).

In the Russian Coach Professional Standard Project, the coaching is defined as "an organization of independent activity of adults to develop and mobilize their internal resources in the context of solving life, professional and business problems" (CPS, 2013)

In the broadest sense, coaching is a form of advisory support, which helps to achieve significant goals as soon as is practicable through the mobilization of internal potential, development of the necessary abilities and the formation of new skills.

It has found expression in the fact that corporations introduce new positions: Chief Knowledge Officer, Vice President for Intellectual Capital, Intellectual Assets Manager, Educational Director, Knowledge Broker (coordinator of knowledge proposal and demand); crossfunctional project teams in the field of knowledge management are formed. 
In the higher education system, it is reflected in the form of emergence of specialized structures, units and specialists in education quality and assurances of the quality of education. The need for knowledge management specialists in corporations and universities was determined by a number of requirements arising from increasing globalization, the increasing use of knowledge and the necessity of its quality control.

Knowledge management specialist or coach prepares programs for the use of corporate knowledge, and is responsible for developing processes which facilitate the teaching and learning. He has two main responsibilities: the creation of corporate information systems and the development of an internal culture of knowledge sharing. In this connection, such specialists develop a comprehensive system for sharing knowledge, develop methods for combining data stored in databases, files and intranets, as well as the informal knowledge of the staff.

The aim of coaching for education quality monitoring and assurance of quality of modular education programs is to ensure the compliance of the content and effectiveness of a modular educational program with the requirements of the regional economy.

In order to achieve the desired results, the coaching for education quality monitoring and assurance of quality of modular education programs is aimed at achieving the following common objectives:

- Capability enhancement

- Creation of alternatives

- meeting expectations (of students, employers, state)

- Achieving clarity in communication

- Time management

- Error analysis

- Problem solving

- Achieving a balance between the personal and professional spheres

There are different approaches to coaching for education quality monitoring and assurance of quality of education, such as information, diagnostic and consulting, developing, activating and others. For clear understanding of all approaches' impact we have provided a characteristic for each of them. The idea of research is in combination of theoretical and practical training, informational, diagnostic and consulting, activating approaches, enabling to implement couching to educational practice of the institution.

The purpose of the information approach is to provide customers using a modular educational program with varied reliable information about its content, the correspondence of the educational program modules to the needs and demands of the regional economy, such as:

- Strategic sessions, educational forums, demonstration workshops, discussion platforms
- Websites that contain information about the professional organizations carrying out evaluation activities, assessment of educational programs

- Internet search engines for the collection, compilation and synthesis of information for management purposes

The purpose of diagnostic and consulting approach is to establish the correspondence of the content of educational programs modules and formed competencies. When applying the above approach for education quality monitoring and assurance of quality of modular education programs, the following methods are used:

- Internal and external audits of the educational program

- Case studies, interviews and questionnaire surveys to determine the degree of satisfaction with the conditions of implementation of educational programs

- Consulting, outsourcing, expertise, marketing, supervision of the educational program

- Use of funds of valuation means, evaluating the quality of education (competences) and education quality assurances (resources)

Also, diagnostic and consulting methods are used in investigating the degree of satisfaction with the conditions of implementation of modular education program.

The purpose of activating approach is to form the inner readiness to independently build one's own educational trajectory. The main feature of this approach is to use elements of interactive technologies that allow updating the situational need for building of the educational trajectory and its correlation with the demands of the regional labor market for all participants of the educational program as per the following vectors:

- Student/teacher/employer

- High school/society/state

The most interested approach in the organization of coaching for monitoring of education quality and assurance of quality of modular education program is the developing approach aimed at the development of skills needed to master a particular profession.

The most exact Russian equivalent of the English verb "coaching" is "development". Thus, the main technique in terms of this approach is an educational counseling (interview, consulting).

Speaking about approaches to coaching, we will note that coaching for monitoring of education quality and assurance of quality of modular education program is a complex phenomenon, the formation of which is still in progress. It can be considered as an information, 
diagnostic, research, prognostic system implemented within the framework of the theory and practice of knowledge management. The main tools of coaching are active listening, questionnaire technologies (effective questions), elements of training, goal setting techniques (SMART model).

The coaching process is based on a GROW model designed to structure the coaching session. GROW model is a sequence of effective questions.

The GROW acronym is formed from English "Goal", "Reality", "Options", "What", which is translated into Russian as "ROST" meaning the following:

- Arrangement of objectives (for coaching sessions, as well as for short-term and long-term business prospects)

- Examination of the current situation in terms of the understanding of reality

- List of opportunities and alternative strategies or operative directions

- Things to be done (it should also be determined when and by whom) and the motivation to get them done

The impetus to the justification of a new practice of coaching for monitoring of education quality and assurance of quality of modular education program based on public-private partnership has been given by CDIO standards, criteria and indicators of the Association for Engineering Education of Russia (AEER) acting as means of its development. For example:

CDIO Standard 1. The general context of the development of engineering education. The standard aims at creating the necessary educational environment in which the theoretical knowledge and practical skills are taught, learned and put into practice.

CDIO Standard 2. CDIO program results. A clear and detailed description of the acquired personal, interpersonal and professional competencies in the creation of products and systems conforming to the objectives of the program and approved by all participants of the program.

CDIO Standard 3. Integrated education plan. A plan describing in details the integration of disciplines included in the CDIO curriculum; description of the desired results of learning the program course, according to the AEER criteria and indicators; recognition of the desired learning outcomes described in the curriculum by teaching staff and students. The education plan should include complementary educational disciplines and make it possible to integrate in the teaching process the personal and interpersonal competences, as well as competences needed to create products and systems; it is necessary to define the relationship in disciplines by modules and the suitable sequence of their study.
CDIO Standard 7. Integrated learning. Integrated learning experiences that lead to the acquisition of disciplinary knowledge, as well as personal and interpersonal competences and skills needed to create new products and systems.

CDIO Standard 8. Active learning methods. Education based on the active practical approach. Active learning is the generation, analysis, evaluation, application of ideas aimed at changing the passive position of a student as a consumer of educational services to an active one. Justification of the choice of pedagogical technologies in each module of disciplines of the education program.

CDIO Standard 11. Education assessment. Assessment of skill learning. Use of a variety of assessment methods creates a wide range of learning styles and increases the reliability and validity of the assessment data. Thus, monitoring of the extent to which the students obtain the desired learning outcomes can be performed with a greater accuracy (Crowley, 2001; CDIO Standards, n.d.).

Availability of coaching enhances the attractiveness of the high school in a difficult situation on the labor market, which gives rise to the demand for such services, in particular for coaching for monitoring of education quality and assurance of quality of modular education program.

Another area of application of coaching in education is the support of organizational changes in the modular educational programs representing a purposefully organized process. "Innovative attack" involves the joint institution/employer activity regarding the supposed changes in the modular program.

Coach's key positions:

- Focus on human development

- Awareness, proactive attitude when dealing with personal, professional and business issues, reflexivity and meaningful activities

- External, neutral attitude of the coach toward the customer and the client of coaching service, noninvolvement in the possible conflict of positions and interests

Coaching remains a service even in cases where the customer is an organization. The necessary condition for coaching is the client-side consent and request for services; there is no coaching without request.

It should be noted that being a developing practice, the coaching is carried out not as an organized training process only, but also as a participation of the university (couching client) in various competitions, public and professional accreditations, specially organized audits (coach organization).

The main methods of public-private partnership in the project management, implementation and teaching the education quality monitoring, assurances of the 
education quality of modular educational program are:

- Coaching Training: Differs fundamentally from the traditional knowledge-focused education: its main feature is learning by doing, mentorship from the side of coach association

- Coaching Supervision: is the analysis and discussion of the work. The analysis of coaching and evaluation of its efficiency are based on observations made during the coaching session: effects of coaching dialogue, comparison of coach's intentions and client's responses etc. In professional associations, the supervision is a key tool to maintain the level of professional work; it is included as a tool to ensure the quality of work.

- Outsourcing: i.e. the use of an external source/resource, is a transfer under contract by an organization of certain business processes or production functions to another company specializing in the relevant field. Examples of outsourcing in the coaching activities are the procedures of public and professional accreditation of educational programs, audits of processes and QMS units

- Expertise in Coaching: for monitoring of education quality and assurance of quality of modular educational program is a study of any issues that require special knowledge and reasoned opinion. The execution of an examination is made by experts specialists, scientists who have special (professional) knowledge necessary to resolve the issues

- Coaching Consulting: is a kind of intellectual activity the main goal of which is to analyze and substantiate the prospects of development and use of scientific, educational and organizational-economic innovations with account of subject area and client's problems. The problems covered by consulting is quite wide, in addition, the specialization of companies providing consulting services may be different: from a narrow one limited to any single type of consulting services (e.g. audit), to a very broad specialization covering a full range of services in this area

- Marketing: is an activity involving a set of institutions and processes for the creation, distribution and exchange of offers of companies that are valuable for the final consumers. In terms of our research topic, it is a type of educational organization's activity aimed at satisfying the social demand regarding the preparation of specialists with specific set of personal and professional qualities

- Consultation: here are definitions of assurances and consultations given by the International Standards for the Professional Practice of Internal Auditing (ISPPIA). Thus, the assurances is "an objective analysis of the available audit evidences in order to provide an independent assessment of the processes of corporate governance, risk management and control in the organization", and consultations are "activities aimed at providing customers with advices, recommendations, etc., the nature and content of which are coordinated with the client, in order to support and improve corporate governance processes, risk management and control, without assuming responsibility for managerial decisions by internal auditors". Comparing these two definitions, we can see the main difference: the assurance means "independent assessment of the processes", when consultations mean "providing advices and recommendations to support and improve processes". The definition of consultations is clarified by the definition given by ISPPIA: "activities aimed at providing customers with advices and to improve the processes of the organization aimed at improving the effectiveness and efficiency, strengthening of systems of risk management and internal control to keep them above the critical level for the organization" (ISPPIA, 2015)

There are some rarely used "consulting products" in coaching for monitoring of education quality and assurance of quality of modular educational program that may be of interest, such as: personal communication, memos, initiative proposals to the department heads regarding possible ways to improve the efficiency and effectiveness of the modular education program.

We should note the practice of creation of "key contact points", i.e. "trusted consultants" of managers. These are staff members specialized in a certain area of professional activity and performing the following duties:

- Informing the head of the educational program (Head of Department, Director of the Master's program) about all significant changes in the supervised sector, both internal (processes) and external (regulation and supervision)

- Regular meetings/sessions with employers in order to discuss, consult and improve coaching for monitoring of the quality of education and assurance of quality of modular education program

There should be other priority activities for the "key contact points", namely, first of all counselling and not guarantees. It is expected that they will participate to the fullest extent possible in collegial bodies, enter into all processes in the department, be involved in the production study, know all the problem areas, openly discuss them and seek solutions together with staff members and heads of departments, visit job sites in order to get directly acquainted with the process. 
Thus, coaching is an activity and training at the same time.

Products of a cooperative work of the coach and the client are the activities and education. The integration of activity and learning and creates changes. The concept of activity is a key concept in coaching, so one of the objectives of coaching is to "catalyze the activities" of the client. Another driving force of the change process is education. Education becomes equipotent and complementing force that generates new resources and expands the possibilities.

The organization of coaching for monitoring of the quality of education and assurance of quality of modular education program, expert interviews and practice of programs implementation show that state-public regulation concerning the content of the educational program is regulated at the is regulated at several levels (Fig. 1).

\section{State Level}

In 2000, the Order of Ministry of Education and Science of the Russian Federation No. 839 from 22.03.2000 established the "Internal University Systems of Assurance of Quality of Preparation of Specialists" contest. The contest was organized by the Federal Service for Supervision in Education and Science (Rosobrnadzor).

The contest was based on the first five criteria of the model of the Russian Federation Government Prize in the field of quality, and in 2001, the Contest Council decided to use all nine criteria of the model. The contest was renamed as "Systems of Quality of Professional Education Institution Graduates Preparation".

In the course of the development and improvement of the Contest model, the requirements set out in the following documents were taken into account:

- European Foundation for Quality Management (EFQM) Excellence Model

- Russian Federation Government Quality Award Model

- European Standards and Guidelines for Quality Assurance in the European Higher Education Area (ESG ENQA)

- International Standards ISO 9000

The competition was held for the purpose of establishing a system of state and social stimulation of educational institutions of higher, secondary and elementary education to motivate them to look for modern management methods to ensure the quality of graduates' education.

The main objectives of the contest were the following:

- Stimulation of activity of educational institutions in the field of vocational education quality assurance
- Elaboration of proposals and recommendations for the development of quality systems in educational institutions

- Assistance in the development of quality management systems for self-evaluation of activity of educational institutions and improvement of the processes of graduates education quality control

The assessment was conducted by the expert commission by nine criteria:

- Role of management

- Policy and strategy

- Use of the potential of teachers, staff members and students

- Rational use of resources

- Management of processes to ensure the graduates education quality

- Satisfaction of employers

- Satisfaction of teachers, staff members and students

- Influence of the educational institutions on the society

- Results obtained by an educational institution.

University became the winner of the contest.

\section{Society/Professional Community Level}

Accreditation of programs is carried out on the basis of professional standards of the specific association. Social and professional associations of quality control in the field of education and assurances of quality of modular education program:

\section{Association for Engineering Education of Russia}

Mission. Improvement of engineering education and engineering practice in all of their aspects related to educational, scientific and technological areas, including teaching, consulting, research, engineering developments, technology transfer, wide range of educational services, public relations, co-operation with industry and business, and integration into the international scientific and educational area. The mission determines the activities of the association (Fig. 2).

The Association activity is based on the idea that engineering education is related to the field of national strategic interests of the Russian Federation and in the conditions of the country's transition to sustainable development, the engineers become key players in the socio-economic sphere of society.

Two engineering programs of Transbaikal State University: "Mining engineering", specialty "Open-pit mining" and "Construction of unique buildings and structures", speciality "Construction of high-rise and long-span buildings and structures" have obtained professional and public accreditation of Association for Engineering Education of Russia for 5 years and "European quality label" of the European Network for Accreditation of Engineering Education (ENAEE). 


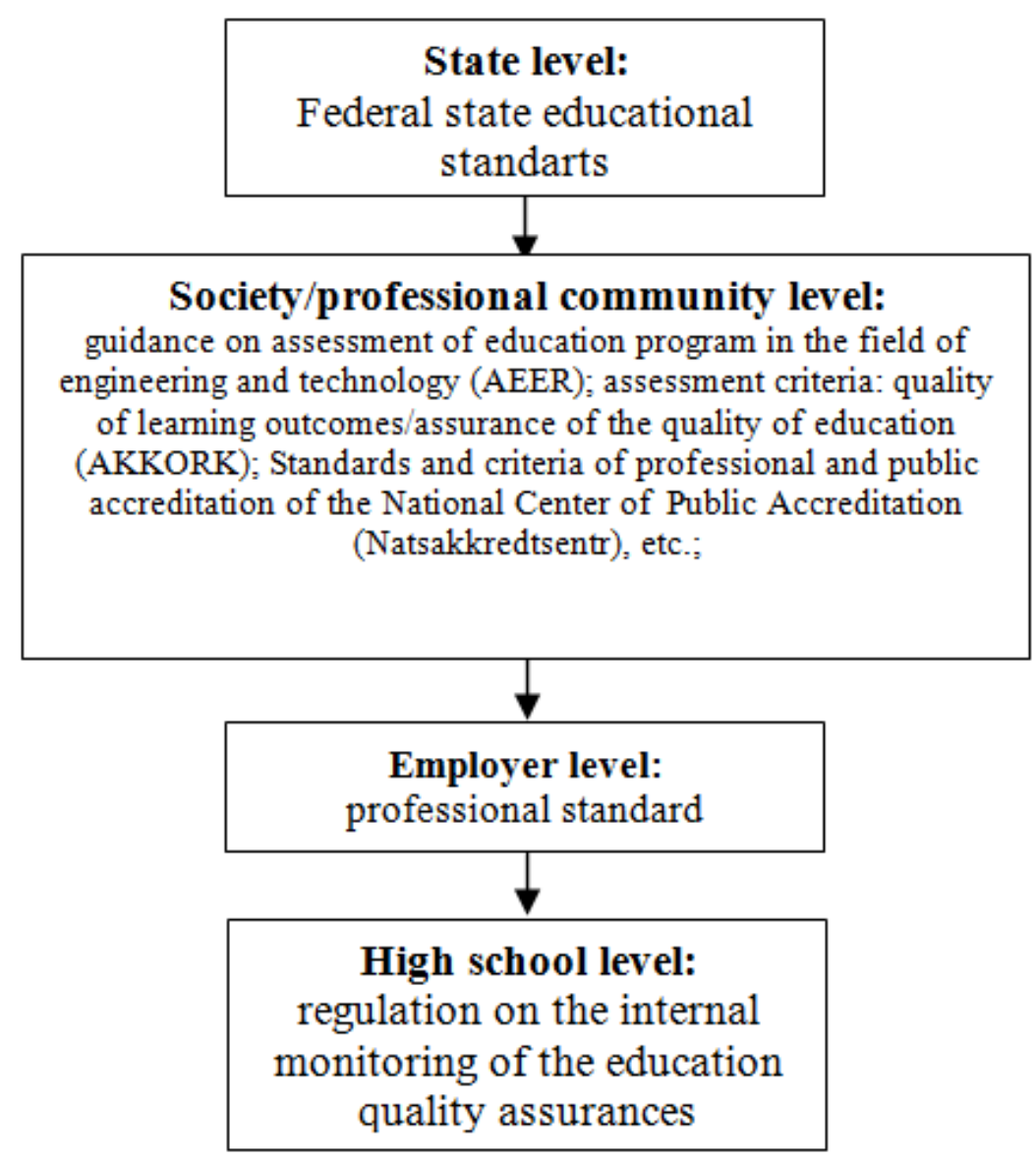

Fig. 1. Levels of state-public regulation solution of educational program issue

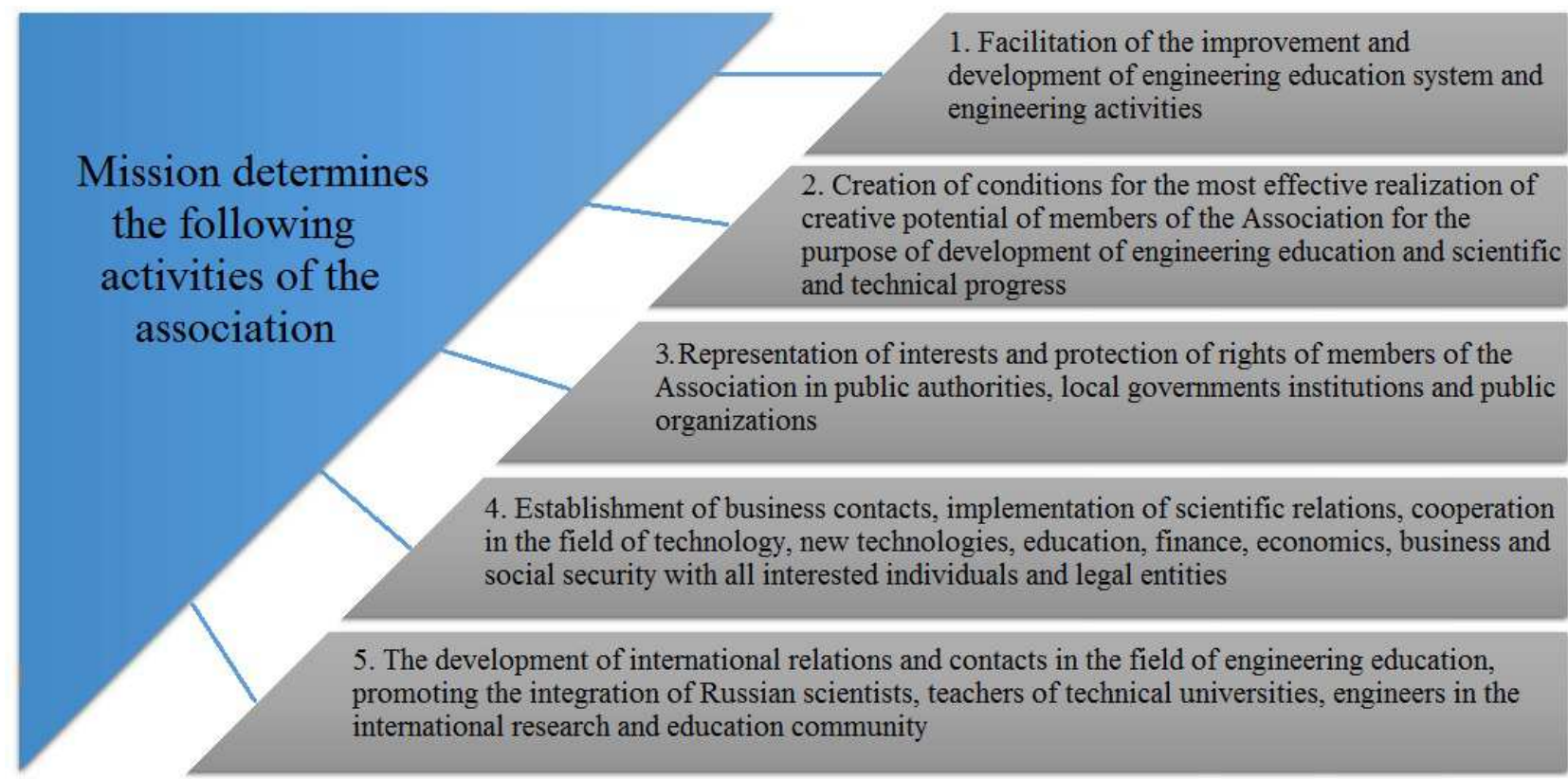

Fig. 2. Areas of activity of AEER 


\section{Agency for Quality Assurance in Higher Education} and Career Development (AKKORK)

The mission of the agency. Formation and development of Russian independent system of assessment of quality and assurances of the quality of education, corresponding to principles of the Bologna Declaration and global best practices (EHEA, 1999).

Key results of cooperation with AKKORK are as follows:

- Synchronization of the learning outcomes related to implemented educational programs with the current requirements of the labor market and industry professional standards

- Strengthening of the internal and external assurances of the quality of education at the level of implemented educational programs and educational organization as a whole

- Optimization of the management system of educational institution

- Improving the performance of the educational institution

- Formation of a quality culture among administrative, managerial and teaching staff

Educational programs of the Transbaikal State University: "Sociology", "Design", "Service" have undergone an examination in accordance with the ESG ENQA and have received AKKORK professional public accreditation.

AKKORK has carried out the independent external quality assessment of the following educational programs: "Information and Communication Technologies and Systems", "Pedagogical Education" (Geography Teacher Education), "Mining Engineering".

AKKORK certification has been gained by the education quality management system of university.

\section{National Center for Public Accreditation (Natsakkredtsentr)}

Its mission is to improve the quality of education, to form a culture of quality in educational institutions and to enhance the image of the Russian education in Russia and abroad through professional public accreditation of educational programs in accordance with European standards of quality assurance of education using European technologies, taking into account the Russian legislation and the best traditions of Russian higher education. The National Center for Public Accreditation carries out the informational and methodological support of procedure of professional public accreditation of educational institutions:
- Coordination and organizational and methodological support of activities of educational institutions in the preparation and gaining of the professional public accreditation

- Elaboration of guidance materials on carrying out and writing report regarding self-examination of the educational institution

- Development of independently established educational standards and criteria for educational programs

- Organization of work on data collection and preparation of the necessary documentation for the professional public accreditation of individual educational programs

Tools of primary data collection are usually based on the self-examination materials and reports. In our case, the determination of the quality of a modular educational program is based on the criteria and indicators of the management of assessment of educational programs in engineering and technology (AEER): learning outcomes; structure and content of the program; educational and methodical complexes; educational technologies and techniques; research activities; educational and material resources; employers participation in the program; students participation in the program; quality of the applicants preparation.

On the basis of the information self-examination results, it is possible to reveal the contradictions, rank the problems and predict changes in a modular educational program.

\section{Employer Level}

Forms of strategic integration interaction are presented in the following public-private infrastructure:

- Coordinating Council for vocational guidance of youth and population (high school - Institute for Educational Development of Transbaikal Territory educational institutions - school boards, parents' committees)

- Scientific-research alliance (Central Scientific Research Laboratory of Priargunsk Mining and Chemical Production Association - mining department of the university); "Geophysics" base department of Transbaikal State University together with Trofimuk Institute of Petroleum-Gas Geology and Geophysics of the Siberian Branch of the RAS

- Social and political alliances of experts and scientists (Public Councils for the independent assesssment of the quality of services, sectoral ministries - high school departments preparing graduates)

- Participation of employers in the design and approval of the modular educational programs 


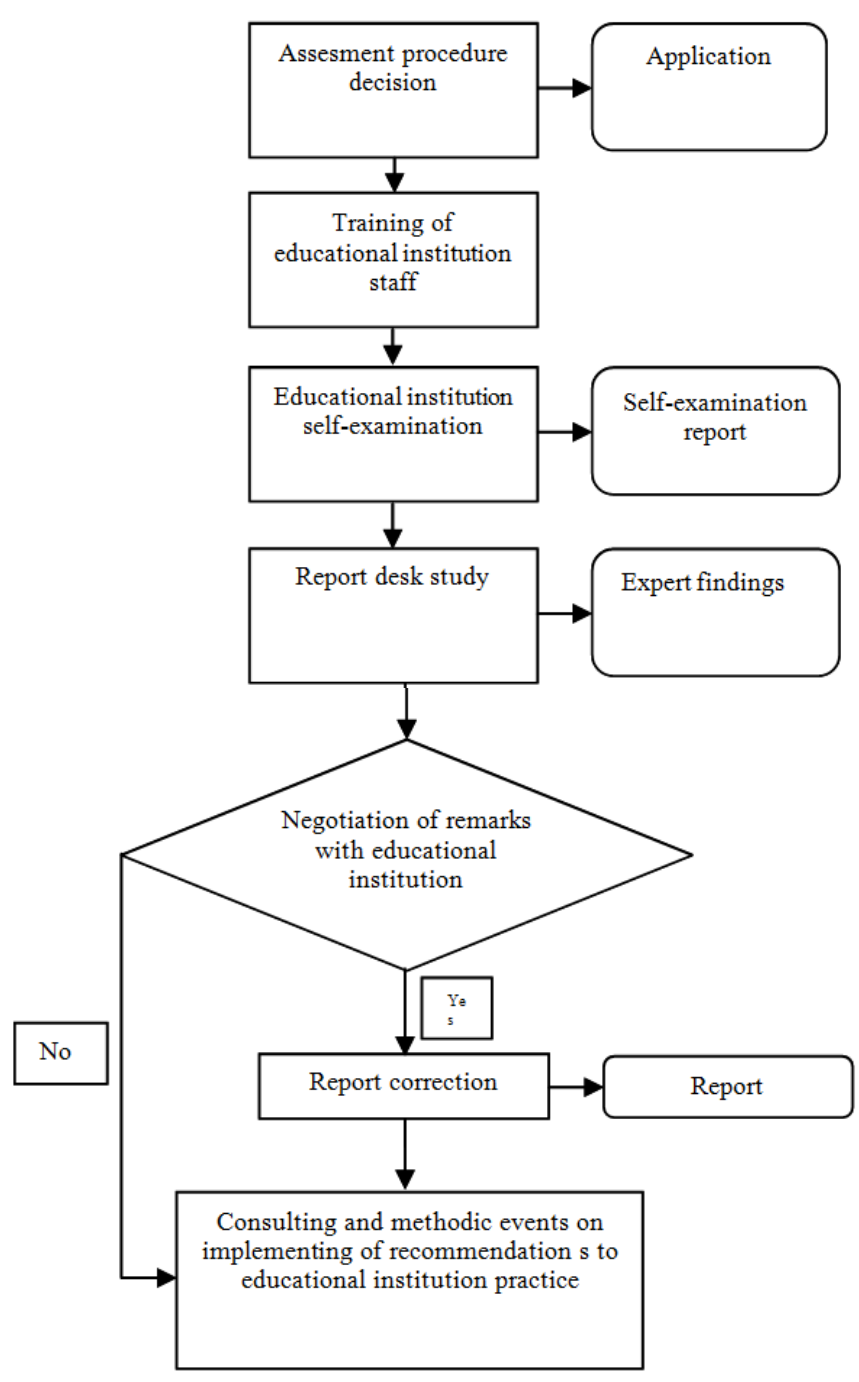

Fig. 3. Steps of coaching for monitoring of education quality and assurance of quality of modular education program

\section{High School Level}

Issues concerning the standardization of key processes are also related to coaching for monitoring of the education quality and assurance of quality of modular educational program. For example, results of the "Admission of students" standardization process were the following documents: Internal high school vocational guidance standard, a comprehensive career guidance program of Transbaikal State University, regulations on vocational guidance activities.

The university carries out activity on coaching of internal auditors, attracting the leading organization in the field of quality management systems: Russian State Social University, Ogarev Mordovia State University, Pastukhov State Academy of Industrial Management.

The training audits were carried out during the implementation of internal audit educational programs.

\section{Discussion}

The need of the transition to coaching as a method of knowledge management is determined by:

- Globalization of education and science, characterized by an increase in the import and export of education and science, the development of international partnerships, mobility growth, loss of "educational sovereignty" (ASI, 2013)

- High school orientation on the economy and society needs, the regional orientation of education and science, the so-called "niche localization

- Practice-orientated education, evaluation of education results through the formed competences and increasing activity component of education

- Digitization of educational and scientific content, automation of routine intelligent operations, allowing building a mass individual "unattended" 
educational process with the use of new technological solutions eliminating the demand for "gramophone teachers

- Accelerating and deepening variability of the world, art and technology determining the need to design such an education that makes the graduate able to solve problems that have not yet been formulated, that may be carried out within the advanced education ideology

- High degree of centralization and formalism in organizations with rigid management structure, where there is a lot of restrictions for the use of knowledge and the fruitful work of innovative groups. They are very slow in the accumulation and use of new knowledge, while the competition requires rapid and accurate response. According to Milner et al. (2006), in the future, the knowledge system will be replaced by the small administrative cells and links between them, there will be a rejection of the rigid management structures

There can be distinguished two options to use coaching in the high school practice: maintenance and support. Working with a professional coach (accreditation agencies, professional associations, partner companies, and others) supports independent development of modular educational program. In foreign practice of higher education, some universities start using the professional coaching services that offer specialized provider organizations. According to David Shaw, Executive Director of a Canadian company providing coaching services, the coaching integration into the university programs is a "perfect example of how the private business and education sectors combine their efforts in order to train students in a better way" (Klarin, 2014) The experience of Transbaikal State University shows that the "built-in" coaching services, such as scientific-research alliance (Central Scientific Research Laboratory of Priargunsk Mining and Chemical Production Association - mining department of the university); "Geophysics" base department of Transbaikal State University together with Trofimuk Institute of Petroleum-Gas Geology and Geophysics of the Siberian Branch of the RAS are useful for the education program consumers as well.

\section{Conclusion}

In the implementation of coaching for monitoring of educational quality and assurance of education quality of modular educational program, we adhere to the following conceptual principles:

- Target-oriented focus on learning outcomes determined together with the employers on the basis of the types and tasks of professional activities, and defined in the form of competencies of graduates based on best national and international practice and the CDIO concept and manifested in the resolution of problem situations. CDIO Standards 2, 3, 6

- Consistent phased implementation of process of formation of competence as a full-scale technological and methodological project of domain-specific competencies improvement and development of personal, interpersonal and professional competencies, based on the use of active methods, integrative educational content and project activities. CDIO Standards 3, 5, 7, 8

- Practice-oriented learning process in conditions of increased volume of production practices and the partial transfer of the educational process to the territory of the plant. CDIO Standards 4, 5, 6

- Criterial and diagnostic determinancy of formed competencies process due to measuring their constituent actions. CDIO Standard 11

- Specificity and measurability of learning outcomes in the form of competencies. CDIO Standard 11

When organizing the coaching for monitoring of education quality and assurance of quality of modular education program based on public-private partnership, we will adhere to the definition given by a professional standard: "Coach is an organization of independent activity of adults for development and mobilization of their internal resources in the context of solving their professional and business problems".

It is important to understand that coaching is an ongoing process, not a one-time event. Knowledge management experts say that the most effective form of coaching is a self-study process. The practice has shown that it is possible to stimulate the process of learning of monitoring of education quality and assurance of quality of modular education program only through the self-examination of the implementation of modular education program.

The introduction of coaching in the educational environment is primarily due to the implementation of monitoring of the quality of education and assurance of the quality of education. Mandatory procedures of such processes are: expertise, accreditation, supervision, outsourcing and quality control.

The training of the university personnel is carried out indirectly in activities (primarily in the course of selfinspection of modular educational programs and activities of the university as a whole). The purpose of monitoring is to obtain recognition, which is impossible to get without continuous improvement and staff training. Training creates new resources, empowers and gives strength for continuous improvement.

Another distinctive feature of the integration of coaching in the system of higher education is the attraction as coach the institutions of public-private partnerships: 
public organizations, professional associations, executive authorities, expert associations and others.

Implementation of educational quality monitoring coaching, modular educational program development assurance based on public-private partnership is a multilevel process (Fig. 3).

The basic steps:

- Submission of the application (for participation in the competition, gaining accreditation, audit, etc.)

- Teaching the educational institution staff the competitive methods, criteria and indicators of public and professional accreditation and audit

- Preparation of self-inspection report by the educational institution

- Desk study of the self-inspection report by experts

- Preparation and presentation by coaching organization of expert opinions for approval of the facts

- Report adjustment (if necessary) in accordance with the information given by the educational institution regarding the facts

- Consulting and methodical actions to implement the developed recommendations in practice of the educational organization (as agreed upon with the educational organization)

\section{Acknowledgment}

The authors gratefully appreciate the support of the Ministry of Education and Science of the Russian Federation.

\section{Funding Information}

The study has been performed as a project part of the public order in the field of scientific activity $(27.2479 .2014 / \mathrm{K})$.

\section{Author's Contributions}

The authors have equally contributed to the conducted research and writing of the article.

\section{Ethics}

This article is original and contains unpublished material. The authors confirm that there are no ethical issues involved.

\section{References}

Adizes, I., 2009. Managing the corporation life cycle. Transl. from English. St. Petersburg: Peter.

ASI, 2013. Education 2035 Foresight. Agency for Strategic Initiatives.
Avdeev, S., 2006. Coaching. Personnel Management, 5: 36-42.

Avetisov, A., 2008. Alfa Coaching. Beta Life. Episode 2. Moscow: Novosti.

Bagdasarian, I.S., 2012. Formation of the manager's communicative competence: Psychological and pedagogic aspects. Monograph. Kransoyarsk: Siberian Federal University Press.

Berulava, M.N., 1999. Pedagogic aspects of the manager's culture of communication. Modern Management, 8: 91-114.

Bezruchko, P., 2003. Coaching in the manager's arsenal. Management Today, 1: 200-219.

Bobrova, I., V. Zimin, N. Plotnikova and I. Lutsenko, 2002. Problems of coaching. New Markets.

Brod, R., 2005. Coaching and mentoring in the professional development of managers: Problems and opportunities. University Management: Practice Analysis, 7: 57-64.

CDIO Standards 2.0. n.d. Retrieved from: Conceive Design Implement Operate.

Chumakova, S., 2013. Russian style coaching. Interview.

CPS, 2013. Coach professional standard. CoachPR. Development of Coaching as a Profession in Russia.

Crowley, E.F., 2001. The CDIO syllabus: A statement of goals for undergraduate engineering education, CDIO report No. 1, Massachusetts Institute of Technology. Conceive Design Implement Operate.

Dobrotvorskii, I.L., 2003. Self-management: Efficient technologies. A practical guidance for solving everyday problems. Moscow: Prior-izdat.

Dovbnya, S., 2003. Who needs coaching. Top Manager, 6: $128-132$.

Downey, M., 2003. Effective Coaching. Lessons from the Coach's Coach. Second edition. Texere.

Dyrin, S.P., 1996. Basic training of future specialists in personnel management. Candidate Thesis in Pedagogics. Kazan.

EHEA, 1999. The Bologna Declaration of 19 June 1999. Bologna Process-European Higher Education Area.

Ermakova, E.P., 2007. Development and implantation of in-house coaching systems into modern organization. Proceedings of International Internet Conference "Intellectual capital and development of Innovative Business in High School in Russia and Foreign Countries.

Ershova, O.A., 2005. Formation of managerial culture as a component of professional competence of a future manager. Candidate Thesis in Pedagogics. Kirov.

Gallwey, T., 1981. The Inner Game of Golf. Jonathan Cape, London.

Gallwey, T., 2000. The Inner Game of Work. Orion Business Books.

Gorshkova, E.G. and O.V. Bukharkova, 2006. Coach mentoring as an instrument of business development. A practical guidance. St. Petersburg: Rech. 
Grant, A.M. and J. Greene, 2005. Solution-Focused Coaching. Transl. from English. St. Petersburg: Peter.

Harris, J., 2003. Coaching: personal development and success. Transl. from English. St. Petersburg: Rech.

ICF Russia, 2008, Code of Ethics. International Coach Federation. Russia Chapter.

ISPPIA, 2015. International standards for the professional practice of internal auditing.

Jay, M., 1999. Coach 2 the bottom line: An executive guide to coaching performance, change and transformation in organizations. Trafford Publishing.

Kimsey-House, H., L. Whitworth and P.H. Sandahl, 2004. Coactive coaching: textbook. Transl. English. Moscow: Maktsentr.

Klarin, M.V., 2014. Coach: Values and meanings of a new profession. Values Meanings, 2: 87-97.

Koval, A.A., 2009. Coaching in managing the personnel of a modern Russian business organization. PHD Thesis. Rostov-on-Don.

Kudriashova, L.D., 1986. Which should the top manager be: Psychology of managerial activity. Leningrad: Lenizdat.

Lapusta, M.G., 2004. Entrepreneurship: Textbook. 2nd Edn., Moscow: Infra-M.

Leonard, T.J., 1998. The Portable Coach. Scribner.

Leonard, T.J., 1998. Working wisdom. Coach U.

Makarov, S.F., 1989. Manager at work. Moscow: Ekonomika.

Maksimov, V.E., 2004. Coaching from A to Z. Everything is possible. St. Petersburg: Rech.

Marshev, V.I., 2010. History of managerial thought: Textbook. Moscow: Infra-M.

Martynov, S.D., 1991. Professionals in management. Leningrad: Vega.

Megginson, D. and D. Clutterbuck, 2004. Techniques for coaching and mentoring. Routledge.

Mescon, M.H., M. Albert and F. Khedouri, 992. Foundations of Management. Transl. From English, By Evenko, L.I. (Ed.), Moscow: Delo.

Milner, B.Z., Z.P. Rumyantseva, V.G. Smirnova and A.V. Blinnikova, 2006. Knowledge management in enterprises: Textbook. Moscow: Delo.

Nenashev, D.V., 2009. Coaching as an effective technology of development of emotional competence of the future managers. Candidate Thesis in Pegagogics. Moscow.

Ognev, A.S., 2003. Organizational consultancy in the coaching style. St. Petersburg: Rech.

O'Neill, M.B., 2005. Executive coaching with backbone and heart. Moscow: MAK.
Parsloe, E., 1992. Coaching, mentoring and assessing. Kogan Page, London.

Prigozhin, A.I., 2003. Methods for organizations' development. Moscow: MCFER.

Reynolds, M., 2003. Coaching: Emotional intelligence: Aim your emotions (EQ) at success in the work. Moscow: Center for Supporting Corporate Management and Business.

Rogachev, S.A., 2003. Coaching: possibilities of applying in business. Moscow: Feniks.

Rybkin, I.V., 2005. Coaching of social success. Moscow: Institute of All Humanities Research Press.

Samolianov, O., 2008. Coaching to the very essence. What is important? St. Petersburg: Rech

Samoukina, N. and N. Turkulets, 2004. Coaching -your guide in the world of business. St. Petersburg: Peter.

Savkin, A. and M. Danilova, 2003. The Russian style coaching: courage for desires. St. Petersburg: Rech Publishing House.

Simonov, V.P., 1997. Pedagogical management: 50 KNOW HOW in the Field of Education Process Management: Textbook. 2nd Edn., Moscow: Rospredagentstvo.

Sorokoumov, A., 2006. Strategies of success in interesting times: Coaching for players in business. Ekaterinburg: U-Faktoria.

Stacke, E., 2006. Coaching for winning teams and successful companies. 100 Ways.

Tarasov, V., 2010. Managerial elite. How we select them and train. Moscow: Dobraya Kniga.

Turkulets, N.K., 2006. Formation of labor motivation and corporate behavior of company's employees using the social and managerial coaching technology. Candidate Thesis in Social Science. Moscow.

Valeva, N.S. and V.N. Galev, 1994. Scientific and pedagogical foundations for training managerial specialists for MP. Kazan.

Vylegzhanina, A.O., 2007. Coach-technologies as a way to ensure the competitiveness of entrepreneurial structures: Author's abstract of Candidate Thesis. Tyumen.

Whitmore, J., 1992. Coaching for Performance. The new edition of the practical coaching. Nicholas Brealey Publishng Ltd.

Whitmore, J., 2001. Coaching is a new style of management and HR administration. Practical guide. Moscow: Finances and Statistics. 